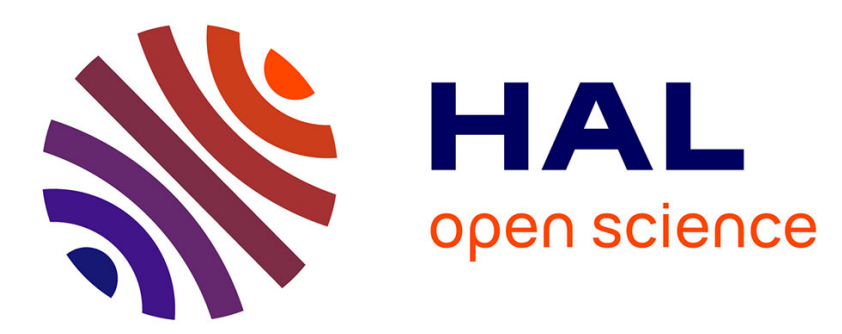

\title{
Influence of Thermal Treatments on the Evolution of Conductive Paths in Carbon Nanotube-Al 2 O 3 Hybrid Reinforced Epoxy Composites
}

Benhui Fan, Delong He, Yu Liu, Jinbo Bai

\section{- To cite this version:}

Benhui Fan, Delong He, Yu Liu, Jinbo Bai. Influence of Thermal Treatments on the Evolution of Conductive Paths in Carbon Nanotube-Al 2 O 3 Hybrid Reinforced Epoxy Composites. Langmuir, 2017, 33 (38), pp.9680 - 9686. 10.1021/acs.langmuir.6b03915 . hal-01842482

\section{HAL Id: hal-01842482 \\ https://hal.science/hal-01842482}

Submitted on 3 Dec 2020

HAL is a multi-disciplinary open access archive for the deposit and dissemination of scientific research documents, whether they are published or not. The documents may come from teaching and research institutions in France or abroad, or from public or private research centers.
L'archive ouverte pluridisciplinaire HAL, est destinée au dépôt et à la diffusion de documents scientifiques de niveau recherche, publiés ou non, émanant des établissements d'enseignement et de recherche français ou étrangers, des laboratoires publics ou privés. 


\title{
Influence of Thermal Treatments on Evolution of Conductive Paths in Carbon Nanotubes- $\mathrm{Al}_{2} \mathrm{O}_{3}$ Hybrids Reinforced Epoxy Composites
}

\author{
Benhui FAN, Delong HE*, Yu LIU and Jinbo BAI* \\ Laboratoire Mécanique des Sols, Structures et Matériaux (MSSMat), CNRS UMR \\ 8579, Ecole CentraleSupelec, Université Paris Saclay, Grande Voie des Vignes, 92290, \\ Chatenay-Malabry, France
}

Corresponding author: Jinbo BAI, jinbo.bai@ecp.fr, Tel. +33 (0)141 131316

Delong HE, delong.he@ecp.fr, Tel. +33(0)1 41131358

\begin{abstract}
The conductive path formed by carbon nanotube $(\mathrm{CNT})$ in polymer matrix is one of the most attractive topics for developing multifunctional nanocomposites. In this study we studied the evolution of conductive paths and interactions in the interfacial regions in epoxy based composites reinforced by urchin-like hybrid of CNTs and alumina microparticles $\left(\mu \mathrm{Al}_{2} \mathrm{O}_{3}\right)$. A homogeneous dispersion of CNTs in the epoxy matrix was achieved thanks to the core-shell structures of CNTs- $\mu \mathrm{Al}_{2} \mathrm{O}_{3}$ hybrids, resulting in interpenetrated epoxy's cross-linking network which strongly bonded with CNTs. Furthermore, thermal treatments at different temperatures around glass transition temperature ( $\mathrm{Tg}$ ) were conducted under vacuum condition on composites near percolation threshold. It was found that the dielectric behavior and the $\mathrm{Tg}$ were shifted in spite of constant CNT's mass fraction used. This was mainly due to the fact that thermal treatment generated the adjustment of cross-linking network of epoxy, and the distances between adjacent CNTs were reduced gradually. This study can provide an insight into the evolution of conductive paths in the interfacial regions from a more straightforward perspective.
\end{abstract}




\section{INTRODUCTION}

The addition of carbon nanotube (CNT) enables to induce fundamental changes from insulation to semi-conductivity for polymer matrix composites when the volume of CNTs $\left(f_{\mathrm{CNT}}\right)$ is approaching to the vicinity value, known as the percolation threshold $\left(f_{\mathrm{c}}\right) .{ }^{[1,2]}$ This transition depends on the evolution of conductive paths in the composite. On the one hand, from the perspective of interfacial polarization, the dielectric performances of wide frequency ranges can effectively detect the evolution of conductive paths since polarizations at different frequencies enable to provide information for molecular motions and structural changes. Especially at low frequency, the significant increase of dielectric permittivity $\left(\varepsilon^{\prime}\right)$ is attributed to the strong interfacial polarization aroused by tunneling effect in the polymer interface between two adjacent CNTs. ${ }^{[3,4]}$ On the other hand, from the perspective of interaction between CNTs and polymer matrix, conductive network is associated with the polymer chain dynamic at the interface region between CNTs and matrix which can be characterized by the glass transition temperatures (Tg). ${ }^{[5-7]}$ The shift of $\mathrm{Tg}$ between neat polymer and polymer matrix in the composite can illustrate the dispersion state of CNTs and the mobility of the polymer in interfacial regions. The shift to a higher temperature usually infers an "attractive" interfaces while to a lower temperature infers a "repulsive" one. The change of magnitude of Tg depends on the thickness of interface, the interparticle spacing and the friction of CNT and polymer in the interface, etc. ${ }^{[8]}$ Therefore, combining dielectric properties and glass transitions of the composite near $f_{\mathrm{c}}$ can provide more interesting and useful details for better understanding the evolution of conductive paths in the composites and the interaction in the interfacial regions.

Actually, the study of conductive paths formed by CNTs and their interfacial interactions has always been attractive which appeals huge amounts of research works [2-4, 8-10] Most of them have been focused on the property's dependence of CNT's content in the various polymer matrices. This is the commonest and most direct way, which provides numerous classical conclusions and fruitful experiences for guiding practical applications, ${ }^{[8-10]}$ but a shortage of this way has to be pointed out is that as 
CNT's content increasing, the system becomes more uncontrolled and difficult due to unavoidable influences from processing and the agglomerations of CNTs. Another kind of study is from the aspect of CNT's surface modification and different interface creations by surfactants and grafting other polymers with short chains. ${ }^{[11-12]}$ However, this way introduces multi-interfaces besides the original CNT-polymer matrix one, which makes the discussion and analysis become more complicated and various. Hence, the discussion on the evolution of CNT's conductive paths from a simple and physical perspective, namely, fixing CNT's content but adjusting the conductive paths in the matrix by the external stimulation can be more reliable and straightforward.

Our previous studies have reported that when the CNTs reinforced polymer composite approaches to $f_{\mathrm{c}}$, the dielectric property is sensitive to the thermal treatment. ${ }^{[13-15]}$ Thus, we take advantage of this sensitivity of dielectric behavior and design suitable thermal treatments based on polymer matrix's glass transition to study the evolution of CNT's conductive paths. The polymer matrix we used in this study is epoxy, which is widely-used in industrial manufactory. The cross-linking nature of epoxy has an advantage compared with linear polymers that it will shrink itself after thermal treatments. ${ }^{[16]}$ This feature makes epoxy matrix composite an ideal candidate because CNT's conductive paths can be altered directly by tailoring matrix's structure. But a basic requirement has to be met is to establish a well-dispersed CNT's network which can interpenetrate with epoxy's cross-linking structure so that the interaction between CNTs and epoxy can be mutually affected. Hence, in order to achieve a well-dispersed CNT's network in the epoxy matrix, a kind of hybrids with a urchin structure is synthesized by chemical vapor deposition (CVD) where $\mathrm{Al}_{2} \mathrm{O}_{3}$ particles is as the core and CNTs grow outsides as the shell. ${ }^{[17,18]}$ Carried by $\mathrm{Al}_{2} \mathrm{O}_{3}$ particles, CNTs can be dispersed homogeneously which makes the $f_{\mathrm{c}}$ of the composite at a low level and remains epoxy matrix's mechanical property. Therefore, in the following parts, by detecting and comparing dielectric and viscoelastic behaviors of the composite before and after annealing treatment, the evolution of CNT's conductive paths and the interaction in the interfacial region will be discussed from both experimental and theoretical aspects. 


\section{EXPERIMENTAL}

\section{Materials and methods}

Spherical alumina microparticles $\left(\mathrm{Al}_{2} \mathrm{O}_{3}\right)$ with the diameter ranging from 1 to $10 \mu \mathrm{m}$ marked as $\mu \mathrm{Al}_{2} \mathrm{O}_{3}$ ( $\mu$ means micrometer scale) were purchased from Performance Ceramic Company (Peninsula, OH, USA). Xylene and ferrocene were purchased from Sigma Aldrich. Epoxy resin (1080S) and curing agent (1084) were purchased from Resoltech Ltd., France.

The synthesis of urchin-like CNTs- $\mu \mathrm{Al}_{2} \mathrm{O}_{3}$ hybrids was carried out by CVD in a quartz tube reactor heated by an electrical resistance furnace (CARBOLITE ${ }^{\circledR}$ ), as reported in reference. ${ }^{[18]}$ The CNT's weight fraction in the $\mathrm{CNTs}-\mu \mathrm{Al}_{2} \mathrm{O}_{3}$ hybrids is $20 \%$ measured by a thermal analyser (NETZSCH STA $449 \mathrm{~F} 3$ ) from 30 to $700{ }^{\circ} \mathrm{C} . \mathrm{N}_{2}$ and $\mathrm{O}_{2}$ flow rates are $60: 60 \mathrm{ml} / \mathrm{min}$ and the heat rate is $20^{\circ} \mathrm{C} / \mathrm{min}$.

The CNTs- $\mu \mathrm{Al}_{2} \mathrm{O}_{3}$ /epoxy composites were processed as follows. First, the hybrids with a calculated amount were mixed with epoxy resin by a three-roll mill (EXAKT 80, Germany). Afterwards, the curing agent was added to the collected suspension at mass ratio of $1 / 3$ to the epoxy resin by manually mixing to obtain a homogeneous suspension. After degassing for $30 \mathrm{~min}$ at room temperature in a vacuum oven, the mixture was poured into an aluminum mold with dumbbell-shape which was $1 \mathrm{~mm}$ in thickness, $50 \mathrm{~mm}$ in length and $4 \mathrm{~mm}$ in gage width. Curing is in the oven of $60{ }^{\circ} \mathrm{C}$ for $15 \mathrm{~h}$. The densities for $\mathrm{CNT}, \mathrm{Al}_{2} \mathrm{O}_{3}$ and epoxy for the calculation of volume fractions are $2.00,3.69$ and $1.14 \mathrm{~g} / \mathrm{cm}^{3}$, respectively. We mark the composite as the form of CNTs- $\mu \mathrm{Al}_{2} \mathrm{O}_{3}$ /epoxy-x\%, and $\mathrm{x} \%$ means with the weight fraction of CNTs in the composite. The concrete contents involving weight fractions of CNTs- $\mu \mathrm{Al}_{2} \mathrm{O}_{3}$ and $\mu \mathrm{Al}_{2} \mathrm{O}_{3}$ and their volume fractions of CNTs are presented in Table 1.

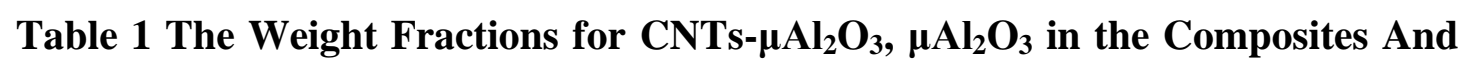
the Relatively Volume Fractions of CNTs in the Composites

Sample Number $\quad w t_{\mathrm{CNTs}-\mu \mathrm{AL} 203}(\mathrm{wt} \%) \quad w t_{\mathrm{MAl}_{2} \mathrm{O} 3}(\mathrm{wt} \%) \quad f_{\mathrm{CNTs}}(\mathrm{vol} \%)$




\begin{tabular}{lccc}
\hline $\mathrm{CNTs}-\mu \mathrm{Al}_{2} \mathrm{O}_{3} /$ epoxy-0.1\%, & 0.5 & 0.4 & 0.06 \\
$\mathrm{CNTs}-\mu \mathrm{Al}_{2} \mathrm{O}_{3} /$ epoxy- $0.3 \%$ & 1.5 & 1.2 & 0.2 \\
$\mathrm{CNTs}-\mu \mathrm{Al}_{2} \mathrm{O}_{3} /$ epoxy- $0.5 \%$ & 2.5 & 2 & 0.3 \\
$\mathrm{CNTs}-\mu \mathrm{Al}_{2} \mathrm{O}_{3} /$ epoxy- $1 \%$ & 5 & 4 & 0.6 \\
\hline
\end{tabular}

\section{Characterizations}

The morphology characterization for CNTs- $\mu \mathrm{Al}_{2} \mathrm{O}_{3}$ hybrids and the fracture surface of CNTs- $\mu \mathrm{Al}_{2} \mathrm{O}_{3}$ /epoxy were conducted by scanning electron microscope (SEM) (LEO Gemini 530). The composites were broken after impregnated in liquid nitrogen for 5 min in order to keep their original matrix states, and the fractured surfaces were coated by a thin layer of gold to increase the samples' surface conductivity.

Dynamic mechanical analysis (DMA) for samples of epoxy and composites were conducted in tension mood by Netzsch DMA 242C. The measurement was conducted from $30{ }^{\circ} \mathrm{C}$ to $150{ }^{\circ} \mathrm{C}$ and with a heating rate of $2{ }^{\circ} \mathrm{C} / \mathrm{min}$ at $1 \mathrm{~Hz}$. The size of the sample for the measurement was $10 \mathrm{~mm} \times 6 \mathrm{~mm} \times 1 \mathrm{~mm}$. The loss tangent for the modulus is defined as $\tan \theta=\frac{E^{\prime \prime}}{E^{\prime}},{ }^{[19]}$ where $E^{\prime}$ and E" correspond to the real and imaginary parts of the storage modulus E, respectively.

The dielectric properties of composites were characterized as a function of frequency by an impedance analyzer (Solartron 1260) at room temperature $\left(25^{\circ} \mathrm{C}\right)$ from $50 \mathrm{~Hz}$ to $10^{7} \mathrm{~Hz}$. The sample's size for the measurement was $10 \mathrm{~mm} \times 10 \mathrm{~mm} \times 1 \mathrm{~mm}$. Before the measurement, silver pastes were applied on both sides of the sample for reducing contacting resistance. The samples are considered as plane capacitors and described by parallel resistor-capacitor (RC) circuit systems. The complex dielectric permittivity $\left(\varepsilon^{*}\right)$ is calculated as follows ${ }^{[20]}: \varepsilon^{*}=\varepsilon^{\prime}-\mathrm{j} \varepsilon^{\prime \prime}$, where $\varepsilon^{\prime}$ and $\varepsilon^{\prime \prime}$ correspond to the real and imaginary parts of the complex $\varepsilon$, respectively. $\omega=2 \pi \mathrm{f}$ is the angular frequency, and $\mathrm{j}=(-1)^{\frac{1}{2}}$, imaginary unit. The dielectric loss tangent $(\tan \delta)$ is defined as $\tan \delta=\frac{\varepsilon^{\prime \prime}}{\varepsilon^{\prime}}$ 


\section{RESULTS AND DISCUSSION}

\section{Morphology Characterization for the Hybrids And the Composite}

The morphology of urchin-like CNTs- $\mu \mathrm{Al}_{2} \mathrm{O}_{3}$ hybrids is presented in Figure 1. As shown in Figure 1 (a), a specific urchin-like structure is observed for CNTs- $\mu \mathrm{Al}_{2} \mathrm{O}_{3}$ hybrids where $\mathrm{Al}_{2} \mathrm{O}_{3}$ particles are as the core and CNTs grow outside as the shell. Figure 1 (b) shows that the diameter range of CNTs is from 50 to $80 \mathrm{~nm}$ and the length range is about tens micrometers.

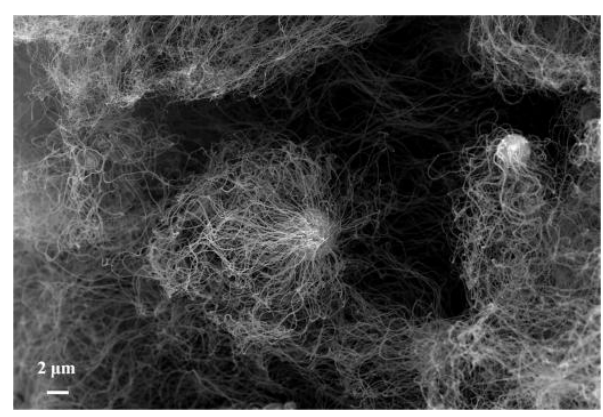

(a)

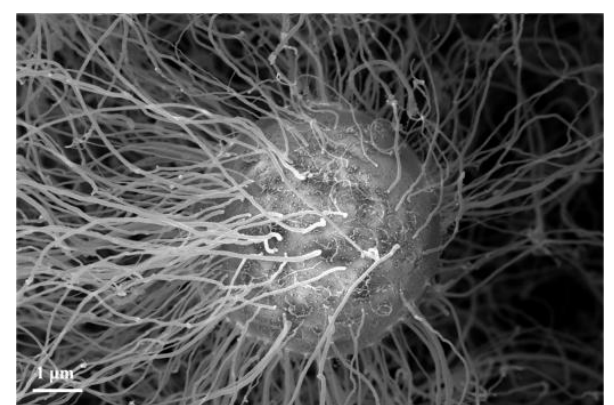

(b)

Figure 1. SEM images for the morphology of urchin-like CNTs- $\mu \mathrm{Al}_{2} \mathrm{O}_{3}$ hybrids

The SEM images for the fracture surface of CNTs- $\mu \mathrm{Al}_{2} \mathrm{O}_{3} /$ epoxy- $1 \%$ are presented in Figure 2. It can be found in Figure 2 (a) that the original structures of CNTs- $\mu \mathrm{Al}_{2} \mathrm{O}_{3}$ /epoxy are partly destroyed after blended by three-roll machine but fortunately, there are still some CNTs remained on the surface of $\mathrm{Al}_{2} \mathrm{O}_{3}$ particles in the composite. Meanwhile, CNTs and $\mathrm{Al}_{2} \mathrm{O}_{3}$ are dispersed in a relative compatible state where they are not separated by the individual agglomerate, which supports the formation of the interpenetrated structure with epoxy cross-linking network. This good dispersion is attributed to CNTs- $\mu \mathrm{Al}_{2} \mathrm{O}_{3}$ hybrid's structure where CNTs array individually on $\mathrm{Al}_{2} \mathrm{O}_{3}$ carriers at first rather than in an initial entangled mode when incorporated into epoxy resin. After blending, such a core-shell structure of hybrids helps CNTs to detach from the carriers and be dispersed into the matrix in a more homogeneous state. Moreover, the addition of hybrids does not destroy the epoxy 
matrix as there are no obvious voids and defects observed in fracture surface. Besides, as shown in Figure 2 (b), there is an epoxy coating layer outside the CNT which indicates that blending processing may enable to form a polymeric interface layer wrapped around the CNT. This provides the evidence for the existence of CNT-epoxy micro-capacitors in the composite which we will discuss in the dielectric part.

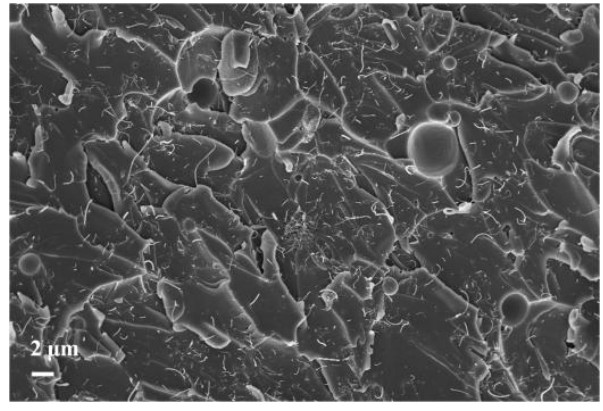

(a)

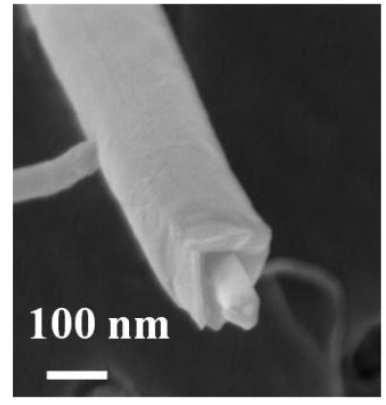

(b)

Figure 2. (a) Fracture SEM image of CNTs- $\mu \mathrm{Al}_{2} \mathrm{O}_{3} /$ epoxy-1\%. (b) The morphology of epoxy layer coating on CNT's surface.

\section{Frequency Dependence of Dielectric Properties of Composites Before Thermal}

\section{Treatment}

The frequency dependence of dielectric property for the composites with different weight fractions of hybrids before thermal treatment is presented in Figure 3. The dielectric properties of composites show strong dependence on tested frequency and CNT's content especially at low frequency range $\left(10^{2}-10^{4} \mathrm{~Hz}\right)$. A dramatic increase in both $\varepsilon^{\prime}$ and $\tan \delta$ can be observed for the sample of CNTs- $\mu \mathrm{Al}_{2} \mathrm{O}_{3} / \mathrm{epoxy}-1 \%$. This can be explained by the classical percolation theory aforementioned. In our system, when CNT's content is low (less than $1 \%$ weight fraction), the epoxy layer isolates the conductive CNTs and the effective conductive paths of micro-capacitors fail to form, which makes $\varepsilon^{\prime}$ at the low level. However, when $f_{\mathrm{CNT}}$ is approaching to the $f_{\mathrm{c}}$, each micro-capacitor is well correlated with the significant increase in the intensity of the local electric field. This usually generates the surface plasma resonance or charges injection at the CNT-epoxy matrix interfaces which promotes the migration and 
accumulation of the charge carriers and consequently cause the interfacial polarization. The shift of peaks of $\tan \delta$ at higher frequency as CNT's contents increasing in the inset graph can also give the evidence for the strong interfacial polarization at low frequency. As we mentioned previously, the dielectric property is very sensitive when the content of CNTs is approaching to $f_{\mathrm{c}}$ which can be a good candidate for studying the evolution of conductive paths and the interaction between CNTs and polymer matrix. Hence, we take advantage of this feature and using thermal treatments on the sample of CNTs- $\mu \mathrm{Al}_{2} \mathrm{O}_{3} /$ epoxy- $1 \%$ based on the results from DMA to compare the change of dielectric properties between before and after.

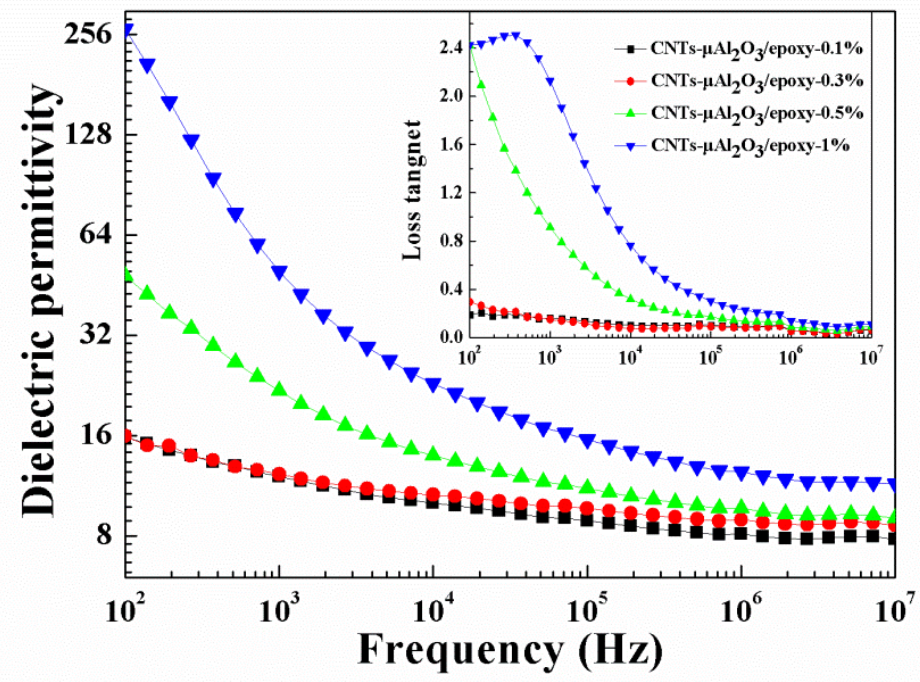

Figure 3. Frequency dependence of dielectric property for the composites with different hybrids content before thermal treatment. The larger one is for $\varepsilon$ ' and the insert one is for $\tan \delta$.

Influences of Thermal Treatment on Glass Transitions for the Epoxy And CNTs- $\mathrm{AAl}_{2} \mathrm{O}_{3} /$ epoxy-1\%

The measurement of viscoelasticity in a temperature's range from 30 to $150{ }^{\circ} \mathrm{C}$ for both epoxy and CNTs- $\mu \mathrm{Al}_{2} \mathrm{O}_{3}$ /epoxy-1\% are conducted by DMA and the results are presented in Figure 4 (a) and (b), respectively. Before the discussion, the thermal treatment procedure is explained firstly as follows: the sample is annealed at the set 
temperature for $1 \mathrm{~h}$ and then cooling to the room temperature naturally. Three annealing temperatures are 100,120 and $140{ }^{\circ} \mathrm{C}$, respectively. Each thermal treatment and DMA measurement is conducted after the sample cooling to the room temperature.

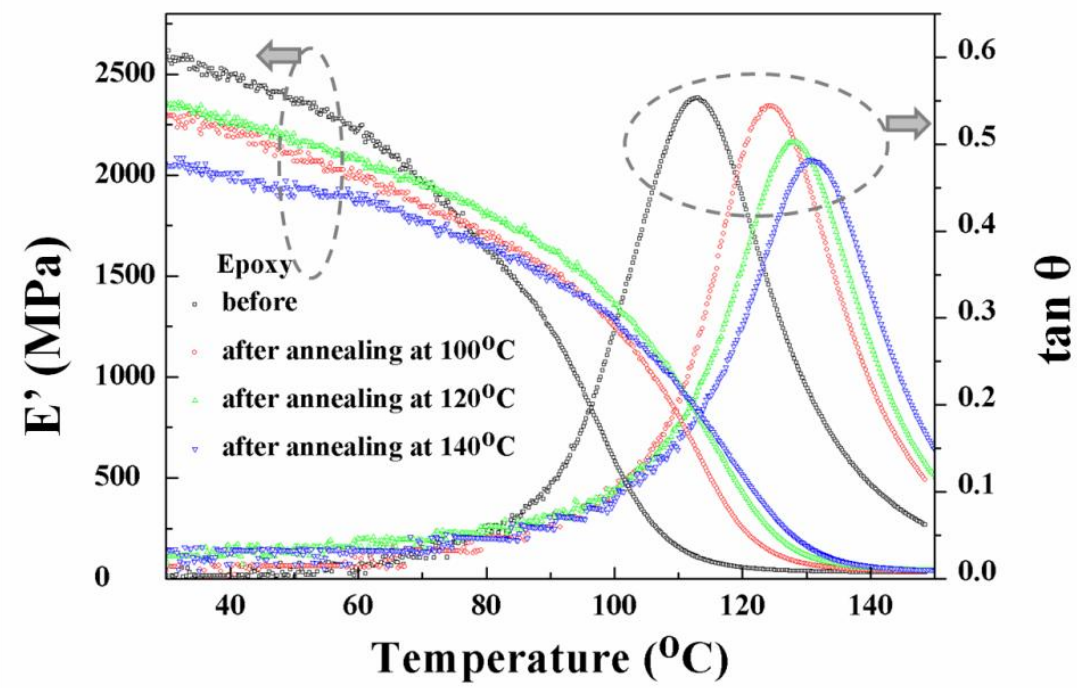

(a)

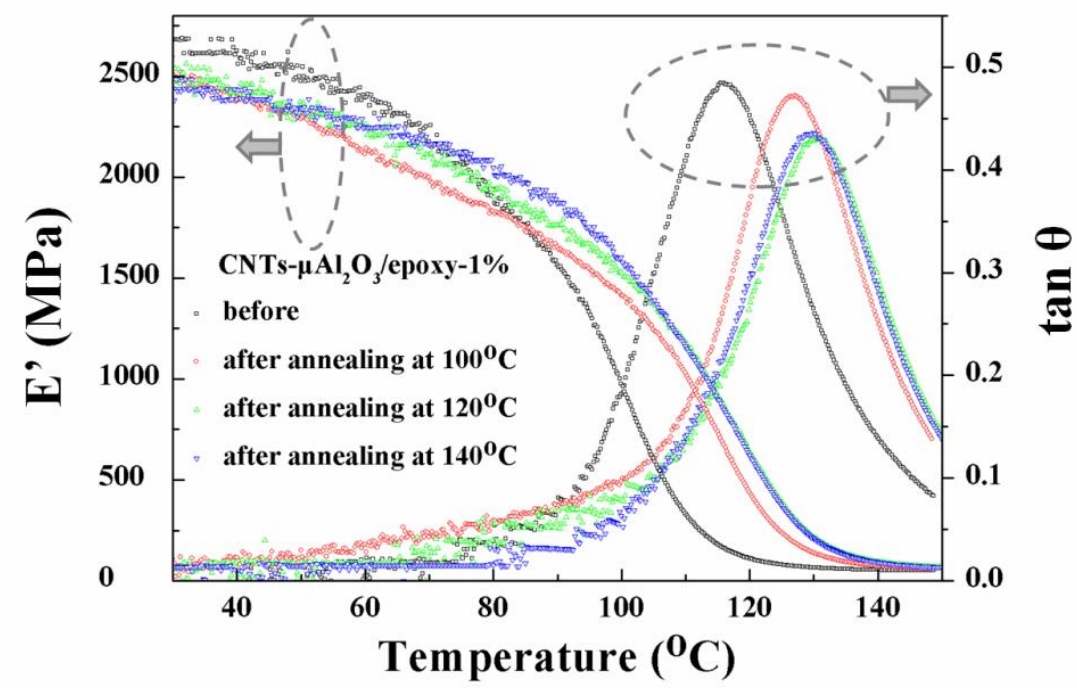

(b)

Figure 4. DMA curves for the epoxy (a) and the CNTs- $\mu \mathrm{Al}_{2} \mathrm{O}_{3} /$ epoxy-1\% (b) 
At first, we discuss the storage modulus (E') of epoxy and the composite which are shown in the left y axis in the two graphs of Figure 4. Before the thermal treatment as shown in the black curves, E' of the composite is a bit higher than that of the epoxy which is attributed to the reinforcement of hybrids. Moreover, after each time's thermal treatment, the plateaus of E' for both epoxy and composite prolong to higher temperature which infers stronger attraction between the cross-linking epoxy and hybrids after thermal treatments. It is known that epoxies cure through an auto-catalytic process. The curing condition used for preparing samples is $60{ }^{\circ} \mathrm{C}$ and $15 \mathrm{~h}$. But curing process actually does not stop once the temperature is high enough to stimulate the remaining reactive sites. The annealing treatment happens to provide sufficient kinetic energy to quickly initiate chemical reactions at even the most hindered locations and give the molecules enough mobility to fill the network which consequently strengthens materials with higher storage modules at higher temperatures. Thus, a more fully formed cross-linking network helps to keep E' and prolong the plateau of $E^{\prime}$ to higher temperature. Besides, the dependence of temperature on the $\tan \theta$ peaks for these two samples shown in the right $y$ axis also have shifts to higher temperatures depending on different annealing temperatures. The peak of $\tan \theta$ demonstrates an important index, $\mathrm{Tg}$, which can evaluate the polymer chains' mobility at interfacial region in the composite. We list the $\mathrm{Tg}$ and the magnitude of $\tan \theta$ according to the curves in figure 4 (b) in the Table 2 for comparing the influence of thermal treatment on the interaction between hybrids and epoxy cross-linking network.

Table 2 Values of Tg And Tan $\theta$ of Epoxy And CNTs- $\mu \mathrm{Al}_{2} \mathrm{O}_{3} / \mathrm{epoxy}-1 \%$

\begin{tabular}{|c|c|c|c|c|}
\hline & \multicolumn{2}{|c|}{ Epoxy } & \multicolumn{2}{|c|}{ CNTs- $\mu \mathrm{Al}_{2} \mathrm{O}_{3} /$ epoxy-1\% } \\
\hline & $\operatorname{Tg}\left({ }^{\circ} \mathrm{C}\right)$ & $\tan \theta$ & $\operatorname{Tg}\left({ }^{\circ} \mathrm{C}\right)$ & $\tan \theta$ \\
\hline Before & 113.1 & 0.554 & 115.5 & 0.485 \\
\hline After $100{ }^{\circ} \mathrm{C}$ & 123.9 & 0.544 & 126.4 & 0.472 \\
\hline After $120{ }^{\circ} \mathrm{C}$ & 128.4 & 0.503 & 130.9 & 0.432 \\
\hline
\end{tabular}




$\begin{array}{lllll}\text { After } 140{ }^{\circ} \mathrm{C} & 130.3 & 0.482 & 130.0 & 0.436\end{array}$

Comparing the values in Table 2, it can be found that in each raw, the $\mathrm{Tg}$ and the magnitudes of $\tan \theta$ do not change much between the neat epoxy and CNTs- $\mu \mathrm{Al}_{2} \mathrm{O}_{3} /$ epoxy- $1 \%$ even after each time's thermal treatment. It may be attributed that the content of hybrids inclusion is not high enough to change epoxy matrix's viscoelastic property thoroughly. However, if comparing the data in each column of the table, it can be found that after each time's thermal treatment, the $\mathrm{Tg}$ of both epoxy and composite shifts to a higher temperature until being stable after the third annealing. Two primary factors mainly affect Tg's shift of the polymer matrix in a composite: the modified mobility of the polymer in the interfacial region and the dispersion state of the fillers. Concretely, the mobility of the polymer in the interfacial region reflects the interaction between the filler and the matrix. Thus a higher Tg after annealing at higher temperatures similarly infers a better interfacial adhesion between hybrids and epoxy due to the more fully cross-linking. Meanwhile, a bit decrease of magnitude of $\tan \theta$ after thermal treatments demonstrates that a lower damping in the epoxy and less viscous loss during the chains mobility.

In order to derive semi-quantitative analysis related to the cross-linking network of epoxy, a procedure of the peak fitting for the curves of the temperature dependence on $\tan \theta$ is followed. The Lorentz peak is assigned to fit the peak of $\tan \theta$ by Origin's fitting routines. The peak factor, $\Gamma$, assessing the homogeneity of epoxy network, is defined as the full width at half maximum (FWHM) of the $\tan \theta$ peak divided by its height (I). ${ }^{[21,22]}$

$$
\Gamma=\frac{\mathrm{FWHM}}{\mathrm{I}}
$$

The calculated results of $\Gamma$ for both epoxy and CNTs- $\mu \mathrm{Al}_{2} \mathrm{O}_{3} /$ epoxy- $1 \%$ are presented in the Figure 5. Basically, the lower peak factor, the better homogeneity will be achieved in the epoxy cross-linking network. ${ }^{[22]}$ As illustrated in Figure 5, after each time's thermal treatment, the homogeneity of cross-linking reduction proves a greater degree of curing reaction occurring. However, differently from the neat epoxy, the 
value of $\Gamma$ for $\mathrm{CNTs}-\mu \mathrm{Al}_{2} \mathrm{O}_{3} /$ epoxy- $1 \%$ increases after annealing at $120{ }^{\circ} \mathrm{C}$ while finally decreases by the third annealing at $140{ }^{\circ} \mathrm{C}$. The difference of $\Gamma$ caused by the annealing comparing with the one for epoxy may infer a stability of the composite's viscoelastic behavior and this stability is possibly attributed to the good dispersion of CNT by hybrids in the epoxy matrix which favors to form an interpenetrating network to support the matrix's cross-linking network. Furthermore, the residual stress from the processing in the sample is also enough released after three times annealing which enables to combine of CNT's conductive network and epoxy cross-linking network in a more stable state. Therefore, the study of the results measured by DMA for both epoxy and CNTs- $\mu \mathrm{Al}_{2} \mathrm{O}_{3}$ /epoxy- $1 \%$ provides a tool to investigate the interaction between hybrids and matrix from the viscoelastic perspective which helps to understand the dielectric behaviors after thermal treatments in the following parts.

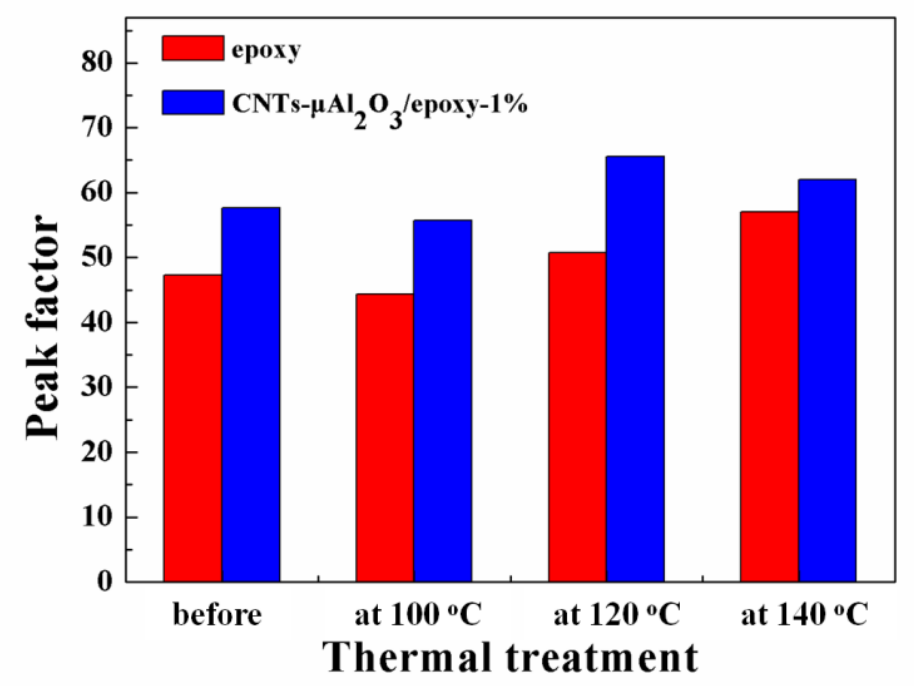

Figure 5. Peak factors calculated by fitting routine of the DMA measurement of the epoxy and CNTs- $\mu \mathrm{Al}_{2} \mathrm{O}_{3} /$ epoxy- $1 \%$

Influences of Thermal Treatment on Dielectric Behavior of the CNTs- $\mu \mathrm{Al}_{2} \mathrm{O}_{3} /$ epoxy-1\% Composite

The dielectric properties of CNTs- $\mu \mathrm{Al}_{2} \mathrm{O}_{3} /$ epoxy- $1 \%$ composites are measured after thermal treatments which is similar as the DMA measurement. The results of 
frequency dependence of $\varepsilon^{\prime}$ and $\tan \delta$ are presented in Figure 6 and Table 3, respectively. The thermal treatment brings an improvement on dielectric property of CNTs- $\mu \mathrm{Al}_{2} \mathrm{O}_{3} /$ epoxy- $1 \%$. After the first and second annealing at $100{ }^{\circ} \mathrm{C}$ and $120{ }^{\circ} \mathrm{C}$ as shown in Table 3, the $\varepsilon$ ' has increased in the whole measured frequency. And if continuing the third thermal treatment at $140{ }^{\circ} \mathrm{C}$, the $\varepsilon$ ' of the composite will decrease a bit and stabilize eventually. The increase of $\varepsilon^{\prime}$ after the thermal treatment is also attributed to the shrinkage of epoxy's cross-linking network which enables to influence epoxy's dipole polarization and the interfacial polarization occurring in the interfacial region between CNTs and epoxy matrix aforementioned. On the one hand, from the perspective of the polymer dipole polarization, annealing at a higher temperature produces a greater degree of cross-linking which affects the relaxation of epoxy's dipoles at high frequency. As a denser network forming, the dipoles of epoxy will mutually affect in an easy mode which favors to arouse the resonance and polarization. But once the cross-linking becoming over dense, the movement of dipoles is restricted by the stiff network and then makes the decrease of $\varepsilon^{\prime}$. As listed in Table 3, the change that $\varepsilon^{\prime}$ at $10^{6} \mathrm{~Hz}$ increases after the first two thermal treatments and then decreases after the third one well indicates the influence of epoxy cross-linking network on epoxy's dipole polarization.

On the other hand, from the perspective of interfacial polarization, this denser structure may induce the shrinkage of the interface layer between two adjacent CNTs so that decreases the tunneling barriers of the electrons which consequently strengthens interfacial polarization and increases $\varepsilon$ ' at low frequency. Thus, the values of $\varepsilon$ ' increase after the first and second thermal treatment. However, it is known that the sample's sensitivity to the thermal treatment is also influenced by its percolation behavior. Once the shrinkage of epoxy's cross-linking becomes over dense, it will also possibly cause the departure of CNTs from other agglomerates and weaken the interfacial polarization. As a result, after the third thermal treatment, the $\varepsilon$ ' of the sample reduces a bit but the decrease is not much since the existence of $\mu-\mathrm{Al}_{2} \mathrm{O}_{3}$ particles can support the conductive paths in the epoxy. The shifting of the peak of tan $\delta$ in the inset graph of Figure 6 to higher frequency also infers a stronger interfacial 
polarization aroused after three thermal treatments. Although the flexibility of epoxy chains becomes less due to forming denser network, but the decrease of the distance between two neighboring CNTs makes interfacial polarization easy to occur and catch up with a higher frequency. Thus, the degree of cross-linking increased by thermal treatments will influence the evolution of CNT's conductive paths and interaction between CNTs and epoxy which consequently affect the dielectric behavior of the composite. We use a schematic in Figure 7 to have a brief summary of this influence caused by the interpenetrated network of hybrids in the epoxy cross-linking network of epoxy.

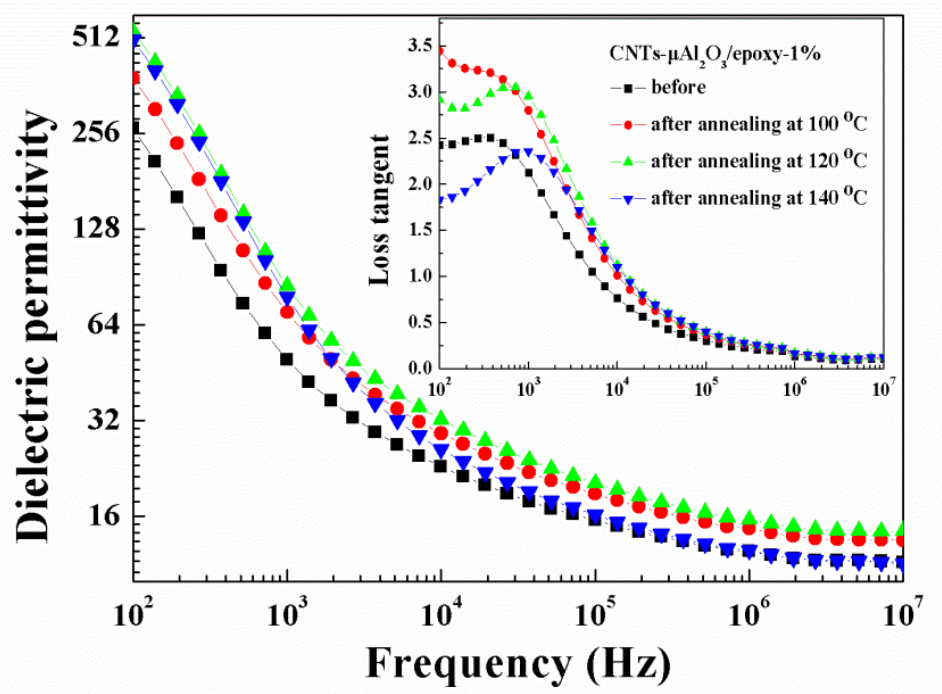

Figure 6. Frequency dependence of dielectric properties for CNTs- $\mu \mathrm{Al}_{2} \mathrm{O}_{3} /$ epoxy-1\%. The inset one is for $\tan \delta$ and the big one is for $\varepsilon^{\prime}$.

Table 3 Dielectric Property of CNTs- $\mu \mathrm{Al}_{2} \mathrm{O}_{3} /$ epoxy-1\%

\begin{tabular}{ccccc} 
& \multicolumn{2}{c}{ At $\mathbf{1 0 0 ~ H z}$} & \multicolumn{2}{c}{ At 10 $\mathbf{H}^{\mathbf{H z}}$} \\
& $\boldsymbol{\varepsilon}$ & $\tan \boldsymbol{\varepsilon}$ & $\boldsymbol{\varepsilon}$ & $\tan \boldsymbol{c}$ \\
\hline Before & 265.9 & 2.43 & 12.43 & 0.14 \\
After $100{ }^{\circ} \mathrm{C}$ & 381.0 & 3.44 & 14.65 & 0.16 \\
After $120{ }^{\circ} \mathrm{C}$ & 533.4 & 2.92 & 15.67 & 0.17 \\
After $140{ }^{\circ} \mathrm{C}$ & 503.0 & 1.83 & 12.50 & 0.17 \\
\hline
\end{tabular}




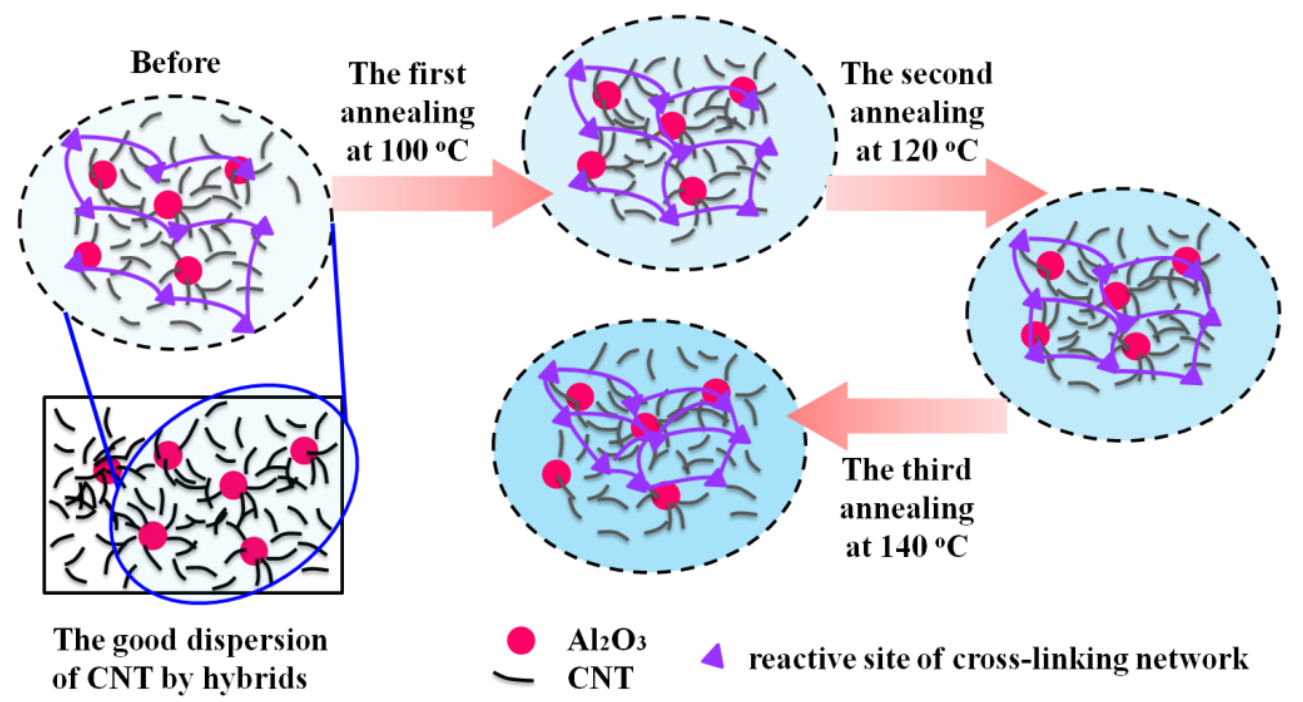

Figure 7. Schematic figure of the evolution of CNT's conductive paths after three thermal treatments in the sample of CNTs- $\mu \mathrm{Al}_{2} \mathrm{O}_{3}$ /epoxy with $1 \%$ weight fraction of CNT

The calculation works based on the combination of the tunneling model with the Reciprocity mixing model is done to illustrate the change of the distance between two adjacent CNTs more directly. ${ }^{[23,24]}$ According to the percolation theory, the electrical conduction of CNT in the polymer matrix composite is primarily governed by the tunneling of electrons through gaps between adjacent CNTs before $f_{\mathrm{c}}$. The tunneling resistance and tunneling conductivity of a CNT's pair with polymer interface between can be approximated by

$$
\begin{aligned}
& \mathrm{R}_{\mathrm{t}}=\frac{\alpha}{\mathrm{A}} \cdot \mathrm{d} \cdot \exp (\beta \cdot \mathrm{d}) \\
& \alpha=\frac{\mathrm{h}^{2}}{\mathrm{e}^{2} \cdot \sqrt{2 \mathrm{~m} \lambda}} \quad \beta=\frac{4 \pi}{\mathrm{h}} \sqrt{2 \mathrm{~m} \lambda}
\end{aligned}
$$

where $\mathrm{m}$ is the mass of an electron, e is the elementary charge, $\mathrm{h}$ is Planck's constant, $\mathrm{d}$ is the distance between CNTs, $\mathrm{A}$ is the cross-sectional area of the junction and $\lambda$ is the tunneling energy barrier height (Epoxy is $1.5 \mathrm{eV}$ ), ${ }^{[25,26]}$ respectively. If we use AC conductivity $\left(\sigma_{t}\right)$ at $100 \mathrm{~Hz}$ to estimate, the equation will change into:

$$
\frac{1}{\sigma_{t}}=\alpha \cdot \exp (\beta \cdot d)
$$


In the case of the CNTs- $\mu \mathrm{Al}_{2} \mathrm{O}_{3}$ hybrids, the conductivity is made by two parts which is schematic in the left above part of Figure 8: one is CNT's conductivity and the other is the conductivity of tunneling effect in an effective distance. We use the series model for the conductivity of CNTs- $\mu \mathrm{Al}_{2} \mathrm{O}_{3}$ hybrids. ${ }^{[24]}$

$$
\sigma_{\mathrm{CNTS}-\mu \mathrm{Al} 2 \mathrm{O} 3}=\left[\frac{1-\varphi}{\sigma_{\mathrm{t}}}+\frac{\varphi}{\sigma_{\mathrm{CNT}}}\right]^{-1}
$$

Where $\sigma_{\mathrm{CNTs}-\mu \mathrm{Al} 2 \mathrm{O}_{3}}$ is the conductivity of CNTs- $\mu \mathrm{Al}_{2} \mathrm{O}_{3}, \sigma_{\mathrm{t}}$ is the tunneling conductivity and $\sigma_{\mathrm{CNT}}$ is the conductivity of CNT $\left(10^{4} \mathrm{~S} / \mathrm{m}\right)$, respectively. $\varphi$ is the ratio of $\sigma_{\mathrm{CNT}}$ and $\sigma_{\mathrm{CNTs}-\mu \mathrm{Al}_{2} \mathrm{O}_{3}}(2 / 3$ is used for the calculation). Similarly, in the case of CNTs- $\mu \mathrm{Al}_{2} \mathrm{O}_{3}$ /epoxy, the conductivity is also made of two parts: one is the conductivity of CNTs- $\mu \mathrm{Al}_{2} \mathrm{O}_{3}$, and the other is conductivity of epoxy. The Reciprocity mixing model ${ }^{[24]}$ is employed for estimating the electrical conductivity of the composite with the random filler's inclusion.

$$
\frac{\sigma_{\text {composite }}}{\sigma_{\text {epoxy }}}=\frac{1+\left(\sqrt{\frac{\sigma_{\text {epoxy }}}{\sigma_{\mathrm{CNTS}-\mu \mathrm{Al2O} 3}}}-1\right) f_{\mathrm{CNT}}}{1+\left(\sqrt{\left.\frac{\sigma_{\mathrm{CNTS}-\mu \mathrm{Al2O} 3}}{\sigma_{\mathrm{epoxy}}}-1\right) f_{\mathrm{CNT}}}\right.}
$$

Where $\sigma_{\text {composite }}$ and $\sigma_{\text {epoxy }}$ are the AC conductivity measured at $100 \mathrm{~Hz}$. The calculated results of the distance's change for before and after thermal treatments are plotted in Figure 8. If we compare data among before and after thermal treatments, we can find that the decrease in distances is around $2 \AA$ in the whole process which is in agreement with other reports. ${ }^{[25,27]}$ This decrease is an average value since the complicated cases including various locations of CNTs, overlapping area at the CNT-CNT junction, CNT's diameter, the thickness of epoxy layer between adjacent CNTs and $\mathrm{Al}_{2} \mathrm{O}_{3}$ 's influence are not considered. But as we have mentioned before, the distance between neighboring CNTs is dependent on the epoxy's cross-linking network. An effective shrinkage of cross-linking network due to the annealing will strengthen the interfacial polarization by tunneling effect and then improve and stabilize the dielectric property of the sample near $f_{\mathrm{c}}$. 


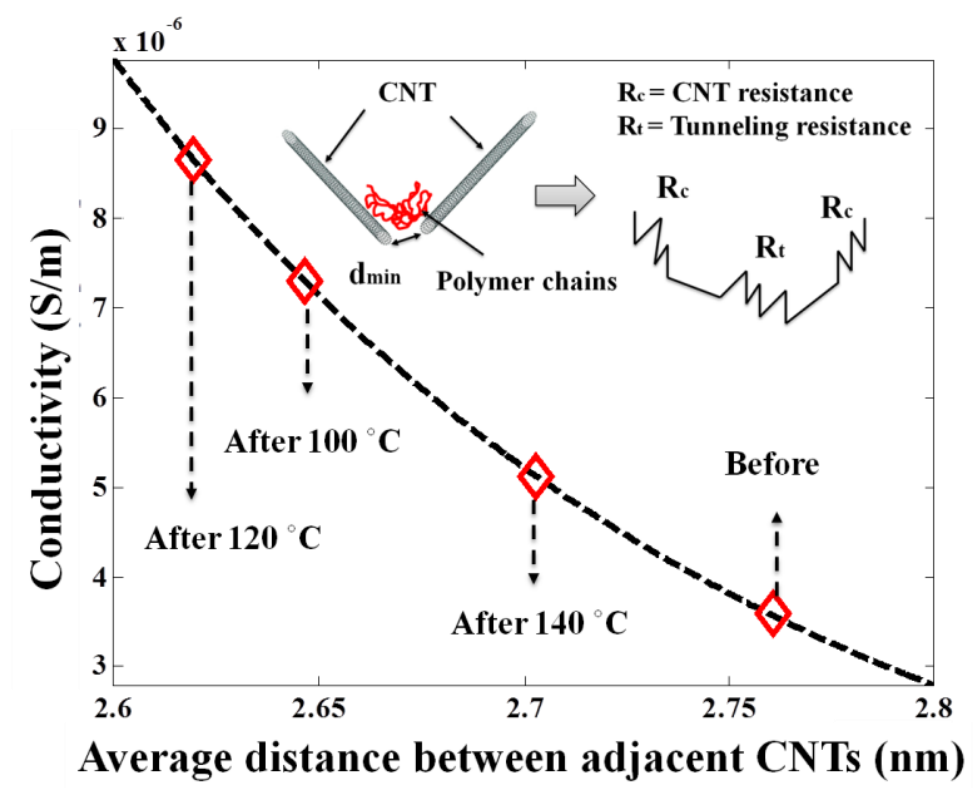

Figure 8. Results of calculating by the tunneling model and the Reciprocity model.

The inset schematic is the CNT's pair with a tunneling gap between.

\section{CONCLUSION}

The altering of conductive paths and the interaction in the interfacial region between CNT and epoxy's cross-linking are key factors for understanding the improvement of dielectric property after thermal treatments. By the effective shrinkage of the epoxy cross-linking network after annealing at the certain temperature, we can observe the evolution of CNT's conductive paths in the composite with a fixed CNT's content. At low frequency of dielectric spectrum, this shrinkage enables to induce tunneling effect and consequently strengthen the interfacial polarization. At high frequency, this shrinkage favors to affect the relaxation of epoxy chains and then reinforce the dipole polarization. Moreover, with the support of hybrid's interpenetrating with epoxy even the cross-linking becomes dense, the dielectric property of composites will still be stabilized at a high level.

\section{ACKNOWLEGEMENT}

The authors thank a lot Mrs F. Garnier for SEM characterization.

\section{REFERENCES}


(1) Lewis, T. J.Interfaces are the dominant feature of dielectrics at the nanometric level. IEEE Trans. Dielectr. Electr. Insul., 2004, 11, 739-753

(2) Dang, Z.M.; Yuan, J.K.; Yao, S.H. and Liao, R.J. Flexible nanodielectric materials with high permittivity for power energy storage, Adv. Mater., 2013, 25, 6334-6365

(3) Nan, C.W.; Shen, Y.; Ma, J. Physical properties of composites near percolation. The Annual Review of materials Research. Annu. Rev. Mater. Res., 2010, 40, 131-151.

(4) Zhang, L.; Cheng, Z.Y. Development of polymer-based 0-3 composites with high dielectric constant, J. Adv. Dielectr., 2011, 4, 1, 389-406

(5) Mangal, R.; Srivastava, S. and Archer, L.A. Phase stability and dynamics of entangled polymer-nanoparticle composites, Nat. Commun., 2015, DOI: 10.1038/ncomms8198

[6] Natarajan, B.; Li, Y.; Deng, H.; L.C.Brinson; Schadler, L.B. Effect of interfacial energetic on dispersion and glass transition temperature in polymer nanocomposites, Macromolecules, 2013, 46, 2833-2841

(7) Sharma, M.; Madras, G.; Bose, S. Cooperativity and structural relaxations in PVDF/PMMA blends in the presence of MWNTs: an assessment through SAXS and dielectric spectroscopy, Macromolecules, 2014, 47, 1392-1402

(8) Song,Y.H.; Zheng, Q. Concepts and conflicts in nanoparticles reinforcement to polymers beyond hydrodynamics, Prog. Mater. Sci., 2016, 84, 1-58

(9) Deng, H.; Lin, L.; Ji, M.Z.; Zhang, S.M.; Yang, M.B.; Fu, Q. Progress on the morphological control of conductive network in conductive polymer composites and the use as electroactive multifunctional materials, Prog. Polym. Sci., 2014, 39, 627-655

(10) Bauhofer, W; Kovacs, J.Z. A review and analysis of electrical percolation in carbon nanotube polymer composites, Compos. Sci. Technol., 2009, 69, 1486-1498

(11) Sahoo, G.N.; Rana, S.; Cho, J.W.; Li, L.; Chan, S.H. Polymer nanocomposites based on functionalized carbon nanotubes, Prog. Polym. Sci. 2010, 35, 837-867

(12) Byrne, M.; Gun'ko, Y. Recent advances in research on carbon nanotube-polymer composites. Adv. Mater., 2010, 22, 1672-1688.

(13) Fan, B.H.; Bai, J.B. Composites of hybrids $\mathrm{BaTiO}_{3} /$ carbon nanotubes/polyvinylidene fluoride with high dielectric properties, J. Phys. $D$ Appl. Phys., 2015, 48, 455303

(14) Fan, B.H.; Bedoui, F.; Weigand S.; Bai. J.B. Conductive network and $\beta$ polymorph content evolution caused by thermal treatment in carbon nanotubes- $\mathrm{BaTiO}_{3}$ hybrids reinforced polyvinylidene fluoride composites, $J$. Phys. Chem., 2016, 120, 9511-9519

(15) Fan,B.H.; Liu, Y.; He D.L.; Bai, J. Influences of graphene nanoplatelet aspect ratio and thermal treatment on dielectric performances of poly(methyl methacrylate) composites, High Volt., 2016, 1-5

(16) Odegard, G.M.; Bandyopadhyay, A. Physical Aging of Epoxy Polymers and Their Composites, J. Polym. Sci. B Polym. Phys., 2011, 49, 1695 - 1716 
(17) Bozlar, M.; He, D.L.; Bai, J.B.; Chalopin, Y.; Mingo, N.; Volz, S. Carbon nanotube microarchitectures for enhanced thermal conduction at ultralow mass fraction in polymer composites, Adv. Mater., 2010, 22, 1654-1658

(18) He, D.L.; Bozlar, M.; Genestoux, M.; Bai, J.B. Diameter- and length-dependent self-organizations of multi-walled carbon nanotubes on spherical alumina microparticles, Carbon, 2010, 48, 4, 1159-1170

(19) Huang, X.Y.; Iizuka,T.; Jiang, P.K.; Ohki, Y and Tanaka,T. Role of Interface on the Thermal Conductivity of Highly Filled Dielectric Epoxy/AlN Composites, J. Phys. Chem., 2012, 116, 13629-13639

(20) Polanský, P.; Mentlík, V.; Prosr, P.; Sušír, J. Influence of thermal treatment on the glass transition temperature of thermosetting epoxy laminate. Polym. Test., 2009, 28, 428-436

(21) Zhou, Y.X.; Pervin, F.; Lewis, L.; eelani, S. Experimental study on the thermal and mechanical properties of multi-walled carbon nanotube-reinforced epoxy, Mater. Sci. Eng. A, 2007, 452-453, 657-664

(22) Bindu, T.K.; Sharmila, E.P. Ayswarya, B.T.; Abraham, P.M.; Sabura, B.; Eby T.T. Fabrication of partially exfoliated and disordered intercalated cloisite epoxy nanocomposites via in situ polymerization: Mechanical, dynamic mechanical, thermal and barrier properties, Appl. Clay Sci., 2014, 102, 220-230

(23) Simmons, J.G.; Generalized formula for the electric tunnel effect between similar electrodes separated by a thin insulating film, J. Appl. Phys., 1963, 34, 1793-1803

(24) Wang, M.R.; Pan, N. Predictions of effective physical properties of complex multiphase materials, Mater. Sci. Eng. R, 2008, 63, 1-30

(25) Rahman, R.; Servati, P. Effects of inter-tube distance and alignment on tunneling resistance and strain sensitivity of nanotube/polymer composite films, Nanotechnology, 2012, 23, 055703

(26) Alig, I.; Potschke, P.; Lellinger, D.; Skipa, T.; Pegel, S.; Kasaliwal, G.R.; Villmow, T. Establishment morphology and properties of carbon nanotube networks in polymer melts, Polymer, 2012, 53, 4-28

(27) Kyrylyuk, A.V.; Schoot, P.V.D. Continuum percolation of carbon nanotubes in polymeric and colloidal media, PNAS, 2008, 105, 24, 8221-8226 
TOC graphic

Tg: $115^{\circ} \mathrm{C}$

$\varepsilon^{6} @ 100 \mathrm{~Hz}: 265$
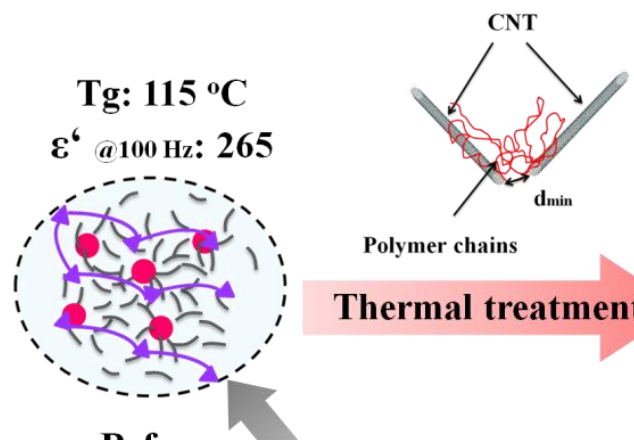

Tg: $131^{\circ} \mathrm{C}$

$\varepsilon^{6}$ a100 Hz: 533

Before

After

Hybrid CNT-Al ${ }_{2} \mathrm{O}_{3}$

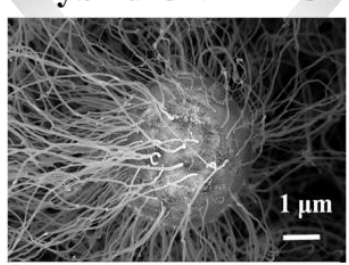

